Reading and Phonological Awareness in Africa

\author{
Katherine J. Alcock \\ Lancaster University, UK \\ Damaris S. Ngorosho \\ Sebastian Kolowa Memorial University, Tanzania \\ Matthew C. H. Jukes \\ RTI International, London, UK
}

Author Information

Correspondence should be sent to Dr. Katie Alcock, Department of Psychology, Fylde College, Lancaster University, Bailrigg, Lancaster, LA1 4YF,

k.j.alcock@lancaster.ac.uk 
Abstract
Keywords: Literacy, Africa, Phonological awareness, Schooling, Unschooled children

Literacy levels in Africa are low, and school instruction outcomes are not promising. Africa also has a disproportionate number of unschooled children.

It has been shown that phonological awareness (PA), especially phoneme awareness, is critically associated with literacy, but there is little evidence about whether PA is gained through literacy, schooling, or both, because most children studied are in education and can read at least letters.

Our previous study of PA and reading in children in and out of school in Tanzania found that PA was associated with reading ability, not schooling or age. Also, many unschooled children learned to read. Here we retested 85 children from the baseline study, on measures of PA and literacy, approximately 2 years later.

We found that more unschooled children had now learned to read but PA had generally not improved in these children. Unschooled children were still poorer at PA than schooled children. At T2, schooling now independently predicted PA and literacy. PA also predicted literacy and vice versa. Explicit phoneme awareness was again poor even in accurate readers. We conclude that more unschooled children have now learned to read, possibly because local literacy is in their first language. However, schooling improves reading and PA. 
Reading and Phonological Awareness in Africa

\section{The state of literacy in sub-Saharan Africa}

Worldwide, $14.5 \%$ of the population live on $\$ 1.25 /$ day while in sub-Saharan Africa the figure is $46.8 \%$ (World Bank, 2015). Not surprisingly rates of literacy are low in general. According to UNESCO (2015b), Africa is the only continent where more than half of parents cannot read sufficiently well to help their children with their homework. In addition, the region has $51 \%$ of the world's out-of-school children despite having only $16 \%$ of the world's population (UNESCO, 2015a).

Formal literacy assessment of primary school children in the region is not more encouraging. In our study country (Tanzania) only $8 \%$ of grade 2 students could answer $80 \%$ of Early Grade Reading Assessment (EGRA) comprehension questions correctly, which is generally taken to be a meaningful comprehension level (Brombacher et al., 2014). Even in less impoverished countries such as South Africa, surveys such as preProgress in International Reading Literacy Study (prePIRLS) find that schools' implementation of reading instruction, and learners' outcomes, are poor (Combrinck, van Staden, \& Roux, 2014). Matjila and Pretorius (2004) have highlighted poor reading skills among South African learners, with mean scores less than $60 \%$ (which they term "frustration level").

Despite this pessimistic assessment of the state of affairs, evidence also suggests that a number of children in Africa learn to read even without formal instruction - in other words, children learn to read without attending school (Alcock, Jukes, Ngorosho, \& Deus, 2010). This paper aims to describe this phenomenon in more detail and to explore its relevance to theoretical issues. In particular it has the potential to contribute to debates about the extent to which formal literacy instruction is required for the development of children's phonological awareness (PA). Before describing the study we review previous research on precursors and consequences of developing PA, including data from the study region. 


\section{Phonological awareness, literacy and illiteracy}

Previously we have investigated literacy and its link to PA in children in and out of school, learning to read in their L1 (Kiswahili), in rural Tanzania (Alcock et al., 2010). The link between literacy/illiteracy, PA, and literacy instruction is a complex one, and we will briefly review the literature while mentioning links to our previous findings.

\section{The structure of phonological awareness (PA)}

$\mathrm{PA}^{1}$ is a multi-component skill which has been strongly linked in recent years to the development of word reading in particular; in turn word reading is one of the necessary skills for reading comprehension. Debate in this area surrounds the nature of PA itself and the direction of influence between literacy and PA. Both of these are relevant to our study.

Some authors suggest that PA is a unitary ability with a single underlying representation (see for example Anthony \& Lonigan, 2004). Others argue that it is a multifactor skill, and in particular that phoneme awareness is the crucial part of this skill that is uniquely linked to reading development. A recent large scale meta-analysis by MelbyLervåg, Lyster, and Hulme (2012) found that the concurrent relationship between phoneme awareness and reading was stronger than, and independent of, relationships between rime awareness and working memory and reading. The authors also concluded that this PAreading relationship was the same in languages with regular orthographies.

Other, longitudinal, studies from the same group show phoneme awareness to be a predictor (not just a correlate) of reading ability, more than other aspects of PA (Muter, Hulme, Snowling, \& Taylor, 1998; Muter, Hulme, Snowling, \& Stevenson, 2004). In illiterate adults, too, phoneme awareness predicts literacy skills following a period of training (Landgraf et al., 2012). This also seems very relevant to the study of literacy in children in the region, in particular for those who may fail to gain literacy due to lack of appropriate

${ }^{1}$ Here, PA stands for "phonological awareness". Where we refer to phoneme awareness, we spell it out. 
education. In our previous work in the study area (Alcock et al., 2010) we examined different components of PA and found that they did not develop evenly in children learning to read in Tanzania. The children in our study almost universally failed to develop phoneme awareness even if they had good word decoding skills. We will examine this further in the current study.

Studies with illiterate adults suggest that literacy to some degree may also be a prerequisite for gaining phoneme awareness skill. Morais, Bertelson, Cary, and Alegria (1986) found that newly literate, but not still-illiterate, adults were able to segment phonemes. Likewise, Loureiro et al. (2004) found that PA was poorer in illiterate than literate adults; only phoneme skills were directly related to literacy ability. Similarly, we found that children in our previous study (Alcock et al., 2010) only correctly answered a maximum of one out of 3 phoneme manipulation items, and that children who could not decode words performed significantly worse than children who could do so.

Confounds in most other study settings make interpretation difficult. Young children in literacy-rich societies may have sufficient exposure or instruction before attending school or formally learning to read that they may be able to gain phoneme awareness, rendering them effectively "literate-like" before they can read. However, adults who remain illiterate may have had previous failures in literacy instruction due to clinically poor PA skills.

With these findings in mind, we examined the relationship between literacy and PA in a study setting where children have minimal exposure to environmental print. Children's instruction in literacy also starts at a variety of ages dependent on parental beliefs about their children's abilities, and factors not related to ability such as the number of siblings, home-toschool distance, and parents' income (Alcock et al., 2010).

\section{Research on PA in sub-Saharan Africa by our group and others}

There has been a small amount of research in PA in the region. Pretorius and Naudé (2002) examined very early phoneme awareness, and pre-literacy skills, among preschool 
South African children. Non-school attending children answered correctly $13.8 \%$ of questions requiring identification/manipulation of phonemes, a surprisingly good performance.

Malda, Nel, and van de Vijver (2014) examined PA and its relationship to reading ability in children learning to read their L1 (Setswana). PA but not short term memory (STM) was related to reading ability, and vocabulary was related to word reading and reading comprehension. Wilsenach (2013) made similar findings comparing Northern Sotho speakers in an English medium school to an L1 medium school. Children instructed in their L1 had a much richer relationship between PA (here syllable awareness), nonword repetition and L1 reading, than children instructed in English. In both studies there was a less strong or nonsignificant relationship between PA and English word reading; this may be due to the orthographic nature of English, or to these children's poor English skills. In our baseline study, we found a significant relationship between reading ability (in children's L1, Kiswahili) and PA ability that was not explained by schooling or age (Alcock et al., 2010).

Grigorenko, Ngorosho, Jukes, and Bundy (2006) examined the relationship between phoneme awareness, phonological STM, and reading skills in L1 instructed Tanzanian school children. Phoneme awareness and phonological STM were associated with word and nonword reading, and with measures of achievement in reading and spelling. Phoneme awareness and phonological STM also predicted reading and spelling achievement at a second time point. In Jukes et al. (submitted)'s study Kenyan children were assessed on one implicit PA measure and there was a small but non-significant difference between intervention schools (where teachers were coached by SMS) and non-intervention schools.

\section{The interaction between home, school and literacy}

As we saw in our previous research, skills that are taught in school can nevertheless be acquired by children who are out of school - many children in our sample who never 
enrolled in school, for example, still learned to read. This is despite low levels of literacy in general among parents, and a lack of environmental literacy materials. We now review skills children gain at home which influence their theoretically school-based literacy acquisition.

\section{Home-learned spoken language skills influence literacy}

Lekgoko and Winskel (2008)'s suggested that some skills are acquired differentially outside school, even to the extent of some skills being acquired in one language and some in another. Musonda (2011) observed a similar range of emergent literacy behaviours in urban Zambian pre-schoolers to that found in some Western settings.

It has been assumed for some time that parental education levels are crucially associated with children's cognitive and educational outcomes. However, it appears to be the specific practices that take place in homes that drive this association (Nampijja et al., submitted). For example, Chansa-Kabali, Serpell, and Lyytinen (2014) found that family literacy activities and attitudes (as well as socio-economic status, SES) predicted literacy in L1 and LoI better than parental education. Ngorosho (2011) also showed that parental literacy practices and materials contributed unique variance to children's literacy in L1/LoI.

From all of these data, it seems that examining what happens in children's homes their preschool L1 skills, and their literacy skills and practices acquired at home - will be fruitful in examining how children acquire literacy in both their L1 and other LoIs. In particular, it is encouraging given the very slow rate of literacy acquisition, and the extremely poor instruction environment observed, that children do acquire literacy practices at home, and that their L1 PA (even where they are not being instructed in this language) is influential.

\section{Work on this study so far}

As already outlined, we have previously studied the relationship between home versus school-learned literacy and PA skills in monolingual Kiswahili speaking children in and out of school in rural Tanzania. Children in this setting have a limited number of years of school, 
and instruction in Kiswahili reading in school is usually rote-learning, whole class chanting, and focuses on syllable awareness (less helpful for decoding than phoneme awareness; Alcock et al., 2010; Melby-Lervåg et al., 2012). However, learning to read an orthographically transparent language such as Kiswahili is a simpler task than an opaque language such as English, and can be described as all-or-nothing with rapid learning once the "code" is cracked (Alcock et al., 2000).

Interestingly in this setting we initially expected that children not attending school would form a comparison group with no literacy or PA skills. We in fact found that many children out of school are nevertheless good emergent readers with letter and word reading skills, and above-chance PA skills (Alcock et al., 2010).

Learning to read had a stronger relationship with PA skills than did school literacy instruction. We used the lack of a one-to-one relationship between schooling and reading to investigate these factors separately. However, we did not find a unique relationship between phoneme awareness and literacy. Children who were accurate readers, and could decode novel words, nonetheless could not perform phoneme awareness tasks (Alcock et al., 2010).

\section{Current study}

The current study followed up the same cohort of children who were previously either in or out of school, two years later. We aimed to determine whether children's initial literacy skills continued to be the only influence on their PA at followup, or whether schooling, children's age (i.e. development independent of schooling or literacy), or initial PA skills now influence PA skills independently. We also wanted to look at the opposite side of the coin - whether it is still only PA that is independently associated with reading ability, or whether age, schooling, or baseline literacy are also predictors. Details of the orthography and phonology of Kiswahili and of literacy instruction in these schools are given in our previous paper (Alcock et al., 2010). 


\section{Predictions based on the PA literature}

We predicted that literacy at $\mathrm{T} 1$ would predict PA at T2. We also predicted that PA skills at $\mathrm{T} 1$ would predict literacy at $\mathrm{T} 2$, in both cases independent to the predictive power of the same abilities at T1. This would replicate findings of previous studies. In our T1 study we had a unique opportunity to discover the independent influences of age and school instruction on PA over and above that of literacy - but we did not find any such influences. We therefore predicted that age and school instruction would still have no independent relationship with PA over and above literacy.

\section{Predictions based on the literature on the interaction between home and school}

\section{skills in the region}

We predicted that children would continue to develop literacy-related skills even when out of school, so that more children would have learned to read between T1 and T2, even those out of school. We also predicted that, based on our findings of poor phoneme awareness skills in all children at T1, PA would be better at T2 overall in children who could read and/or were in school, while phoneme awareness would still be poor even in children who could read and/or were in school.

\section{Method}

\section{Participants}

Participants were children who had taken part in the baseline study (Alcock et al., 2010). Of 101 children who completed PA testing at T1, 16 failed to attend PA or literacy testing at T2, leaving 85 children (39 girls) tested on both domains at T1 and T2. T2 testing took place a mean of 27.7 months after T1 testing (range 25.3 to 32.8 ; s.d. 1.49). These children had a mean age at T2 of 11.96 years, range 10.06 to 13.69 . The number now in each combination of age band, gender and schooling status at T1 and T2 is shown in Table 1. Parents or guardians gave informed consent again at T2 and children gave assent 
again. The consent process again included meetings in each village where children resided.

\section{Materials}

Background information. Children's schooling status at T1 as collected from school records, and age as recorded at $\mathrm{T} 1$ from the best available source, were reused at $\mathrm{T} 2$.

Schooling status at T2 was collected by asking children whether they were currently enrolled in school. Children's families' SES and parental educational experience and attitudes to education were assessed at T1 and this measure was also included in T2 analyses. See Alcock et al. (2010) for further details of these measures, including the range of sources used to determine date of birth as accurately as possible.

\section{Tests of literacy, PA and cognitive ability}

PA tests. Children were all tested using the same set of tasks as in the baseline study. Briefly, these comprised

1. Easy response/implicit PA tasks that asked children to identify the odd one out from three, asking children to discriminate initial phoneme, initial syllable, and final syllable.

2. Intermediate difficulty PA tasks that asked children to count words, syllables, or phonemes.

3. Difficult response/explicit PA tasks that asked children to blend or segment words, syllables or phonemes.

4. Nonword repetition.

Reading tests. These are described in Alcock et al. (2000) and Alcock et al. (2010) and consist of a letter/non-letter decision task ("letter reading"), a word-nonword decision task ("word reading"), and a sentence comprehension task ("sentence reading"). The letter and word decision tasks were also administered at $\mathrm{T} 1$ and the sentence comprehension task was added at T2. Children's scores on these are calculated as significantly above, or not significantly above, chance levels (see Alcock et al., 2010 for further details). 
Cognitive measures. At T1 a verbal multiple choice vocabulary task, Digit Span and Ravens Coloured Matrices were administered. The vocabulary task was repeated at T2.

\section{Procedure}

All of these tests are described further in Alcock et al. (2010) and were constructed and administered in Kiswahili. PA tasks and the vocabulary task were administered by a local tester one-to-one. As at T1, children were asked to attend a testing session in a nonschool location (e.g. village offices) not wearing school uniform, to assist with blinding.

\section{Results}

\section{Differences between children in and out of school on PA tasks}

As at T1, there were children who could read letters, words, or both at above chance levels (see Reading tests, above) who were currently out of school, including those who had never been in school. The numbers of children of each age, gender and schooling status who can read letters and words are shown in Table 1. Because there were so few non-readers (who could not recognise letters or words) we are not able to carry out an analysis precisely comparable to the analysis at $\mathrm{T} 1$ of readers versus non-readers.

It will be noted that children who are out of school and can read include those who learned to read out of school (out of school at both time points), and that there are few children $(\mathrm{N}=3)$ who remained in the sample but dropped out of school. Given the low number of children enrolled at T1 but dropped out by T2, we did not ask those out of school at both time points whether they had been in school briefly between these times, but it seems likely that any falling into this category would be few.

\section{[Table 1 about here]}

We analysed the difference in PA ability between those who were currently in school, and those who were out of school, including in the latter group the small number of dropouts. Descriptive statistics for PA and cognitive tasks, together with significant differences 
between children in and out of school, and the proportions scoring differently from chance where this can be calculated, are shown in Table 2.

[Table 2 about here]

\section{Analysis of levels of PA tests and schooling and reading status}

From the comparisons above it can be seen that children currently in school scored significantly better than those out of school on some, but not all, PA tests. Because there were so few non-readers at $\mathrm{T} 2$, the difference between reading groups could not be analysed as it was at T1. In addition, children's age at T2 no longer correlated significantly with overall score on the PA tasks, $r(85)=.048, \mathrm{p}>.05$.

A comparison of groups of tasks of the same level of difficulty between children in and out of school was however possible. ANOVAs were carried out to examine the differences between schooling groups on all three easy response (odd one out) PA tasks, all three counting PA tasks, and the two manipulation PA tasks. Significant main effects of task and schooling group were found for the odd one out tasks, $F(2)=3.52, p=.032, \eta^{2}=.043$ for task and $F(1)=6.02, p=.016, \eta^{2}=.072$ for group. A main effect of group was found for the counting tasks, $\mathrm{F}(1)=7.73, \mathrm{p}=.007, \eta^{2}=.088$, and for the word manipulation tasks, $\mathrm{F}(1)=$ 11.27, $\mathrm{p}=.001, \eta^{2}=.134$. No significant interactions were found.

At T1 it was found that few children succeeded at the most explicit level of phoneme awareness task, the phoneme segmenting task; this applied also to accurate readers at T1. At T2 data for the subtasks of the Segmenting tasks (segmenting syllables versus phonemes) were unfortunately not separately available but in order to score 10 through 12 in total on the Segmenting task a child would have to get one of the phoneme segmenting items correct. Just 5 children out of 85 scored 10-12 on the Segmenting task at T2; the modal score was 9, with the distribution being somewhat bimodal. These data are shown in Figure 1.

Even at this older age, with most children competent word decoders, very few 
children appear to be able to segment phonemes. Children out of school, although many are accurate readers, are poorer at other PA tasks too, but this group difference does not significantly interact with task type.

\section{Improvement in PA in children who have never been in school}

An ANOVA was carried out examining T1 to T2 changes in different difficulty levels of PA tasks in children who were out of school at both times. A significant main effect of time was found for the odd-one-out tasks, $\mathrm{F}(1)=36.05, \mathrm{p}<.001, \eta 2=.77$, but no effect of task type or interaction. For the counting tasks there was an interaction between task and time, $\mathrm{F}(2)=4.55, \mathrm{p}=.021, \eta 2=.27-$ counting syllables was performed more poorly at $\mathrm{T} 2$ than T1 but counting sounds was performed better. No main effect of time was found for counting or word manipulation. For the manipulation tasks no significant effect of task was found, nor any interaction.

Children who have never been formally instructed in literacy seem to make very limited improvements in PA over time. Independent relationships between literacy, schooling and PA will now be examined in a series of correlational and regression analyses.

\section{Correlational and regression analysis}

Zero order correlations were carried out to examine the links between a) T1 and T2 PA and demographic/SES, literacy, and cognitive measures and b) T1 and T2 reading ability and PA, demographic/SES and cognitive measures. The outcome measure of PA used was the mean z-score for all PA tasks and the measures of reading ability used were the accuracy scores for word and sentence reading. Variables that significantly correlate with T1 PA and reading are shown for comparison; the $\mathrm{T} 1$ variables are not outcome variables here.

\section{Correlations with PA scores}

Significant correlations only are shown in Table 3. PA at neither time point correlated significantly with T1 Raven's Coloured Matrices, with parental educational experiences or 
attitudes, with SES factors, or with distance from school.

\section{Correlations with reading scores}

Significant correlations are also shown in Table 3. Word reading at neither time point correlated significantly with gender, age, T1 Ravens Coloured Matrices score, mother's educational experience and attitudes, or SES factors. T2 sentence reading accuracy did not correlate with gender, T1 Ravens Coloured Matrices score, nor with any parental educational experience or attitude measure or SES factors.

[Table 3 about here]

\section{Regression analyses}

At T2 our main outcome variables were T2 PA, and T2 word and sentence reading accuracy. A multiple regression analysis with each of the significantly correlated independent variables was carried out for each of these outcome variables. In each case, the equivalent score at baseline (T1 PA for T2 PA, and T1 word reading for T2 word and sentence reading) was entered in the first step together with those schooling and reading (for PA) and PA (for reading) variables that were significantly correlated with the respective T2 outcome variable. Then, in a second step, cognitive and environmental independent variables that were significantly correlated were entered.

All models were significant (for the analysis with T2 PA as an outcome, $\mathrm{R}^{2}=.72, \mathrm{p}$ $<.01$, for $\mathrm{T} 2$ word reading as an outcome, $\mathrm{R}^{2}=.58, \mathrm{p}<.01$, and for $\mathrm{T} 2$ sentence reading as an outcome, $\left.\mathrm{R}^{2}=.42, \mathrm{p}<.01\right)$, but step 2 did not add significance for any model.

For the model with T2 PA as the outcome, in both step 1 and step 2, T1 PA and T1 schooling significantly and independently predicted T2 PA, $\beta=.60, \mathrm{t}(58)=5.05, \mathrm{p}<.001$ for T1 PA and $\beta=.20, t(58)=2.31, p=.025$ for $\mathrm{T} 1$ schooling.

For the models with $\mathrm{T} 2$ word reading and $\mathrm{T} 2$ sentence reading as outcomes, but with all variables included as predictors, no single variable emerged as a significant predictor. 
However, examining colinearity statistics showed that in these two regressions, the variance inflation factors were relatively high (over 3) for both PA variables, in each case. Excluding T1 PA from these regression analyses led to $\mathrm{T} 2$ word reading being significantly predicted by $\mathrm{T} 2 \mathrm{PA}, \beta=.29, \mathrm{t}(58)=2.12, \mathrm{p}=.038$, and T2 schooling, $\beta=.44, \mathrm{t}(58)=4.12, \mathrm{p}<.001 . \mathrm{T} 2$ sentence reading was now significantly predicted by T2 PA, $\beta=.32$, t $(58)=2.04, \mathrm{p}=.047 \mathrm{~m}$ and by $\mathrm{T} 1$ schooling $\beta=.24, \mathrm{t}(58)=2.08, \mathrm{p}=.043$.

\section{Discussion}

\section{Changes between baseline and followup}

The children who participated in our study of reading and PA in and out of school, in rural Tanzania, continued to develop in their literacy abilities between T1 and T2, for the most part even where children were out of school at both time points. In addition, children who were out of school at T1 were likely to be in school at T2.

Few children who were still available for testing had dropped out of school at T2. Almost all children, including those were out of school at both time points, could now perform at above chance levels on our word/non-word discrimination literacy task, at T2. In fact, it was no longer possible to compare readers and non-readers based on this measure, implying that almost every child was now a functional "decoder" in this regular orthography, whether or not they had been to school. This confirms our prediction that literacy would have improved at T2 even in children who had never been to school.

In contrast, improvement on PA tasks in children out of school was mixed. Only some tasks showed significant improvement between $\mathrm{T} 1$ and T2. It is a limitation of our study that we did not determine whether children out of school at both T1 and T2 had briefly attended school in between, however.

\section{Findings and implications for literacy, PA and language of instruction}

In this area, children's language of instruction is their L1 and anecdotally at baseline 
we heard from children who were out of school that they had learned to read from siblings and friends who did attend school. In areas where children are not taught in their L1 reading can be extremely poor even after several years of classroom instruction (Combrinck et al., 2014; Trudell, Dowd, Piper, \& Bloch, 2012). These authors highlight teacher training, teacher capacity, enjoyability and poor assessment as stumbling blocks to literacy. While children out of school are clearly not learning from trained teachers, they gain from one-toone attention and potentially from enjoyability. Both children in and out of school can also benefit from self-teaching through phonological recoding (Share, 1995).

Our findings tie in with those of Williams (1998), Laguarda and Woodward (2013), and Heugh (2009), all of whom were able to compare L1 as LoI with a distant L2 as LoI, and found better reading skills when L1 was the LoI. Likewise they agree with Lekgoko and Winskel (2008) and of Musonda (2011) that, even in low literacy environments, children can gain skills at home that aid their literacy development.

However, children's literacy-related abilities are not exactly equivalent if they are in or out of school. At T2, we compared children who were in school with those who were still out of school on PA measures. We found that children out of school differed from those in school on the majority of tasks, with no interactions found between task type and schooling group. Children out of school had also gained few PA skills between T1 and T2. It seems that children who are in school, at this time point, are better at PA tasks in general than those who are not. Children who are out of school can still perform adequately on some PA tasks; not only can children out of school gain some literacy but also some PA.

All children continued, however, to perform poorly specifically on a proxy measure for explicit phoneme awareness. At baseline, almost no children could segment phonemes; no child got more than one item out of three correct. The same task had a bimodal distribution at followup, with almost all children achieving a score indicating that larger phonological 
segments are segmented correctly, but not phonemes. These children who are now all competent decoders, and even if at school, still appear unable to explicitly manipulate phonemes. It would have improved the study if a direct measure of explicit phoneme awareness had been available, however.

\section{Examining the relationships between measures}

We predicted that, since schooling was not related to T1 PA, there would be no further influence of schooling on T2 PA. However, the main independent predictors of T2 PA in this group were T1 PA and T1 schooling.

We also predicted that, based on the literature and our findings at T1, T1 PA would predict T2 literacy. In fact the main independent predictors were PA and schooling. T1 PA was so closely related to T2 PA that independent relationships could not be determined, but when analysed separately T2 PA independently predicts reading accuracy.

As most children could decode words at above chance levels at T2, we introduced a more sensitive reading measure at T2, sentence reading. Sentence reading had the same associates (PA and schooling) as word reading. The lack of relationship between PA at T1 and either word or sentence reading at $\mathrm{T} 2$ was therefore not because we used a reading task (word reading) on which they performed at ceiling level, since they were not at ceiling level on sentence reading.

At baseline the main associations were between PA and reading, reciprocally. Now that reading has become established, schooling becomes additionally important. We will discuss further this finding and the possible reasons behind it below.

\section{Conclusions - What does this add to work on PA regionally and generally?}

Previous studies suggest that children can gain PA skills, including some phoneme manipulation skills, before attending school and/or learning to read (Pretorius \& Naudé, 2002). However, previous studies have not been able to separate the influence of reading and 
schooling, because education is universal in the study settings, and in some cases because children's baseline literacy skills are not reported (Bryant, MacLean, \& Bradley, 1990).

Both our earlier and our more recent study confirmed the that children who are not attending school can perform PA tasks to some level. We have found at this time point that some PA skills fail to improve in children who are out of school, even though the majority are now accurate word readers. There is also a significant and independent influence of schooling experience on T2 PA.

We likewise found an independent relationship between PA and T2 literacy, was not accounted for by the relationship between $\mathrm{T} 1$ and $\mathrm{T} 2$ literacy. We found no independent relationship between children's oral vocabulary and their literacy abilities, unlike Malda et al. (2014) who noted that both PA and vocabulary contributed to literacy.

More generally, PA research suggests that without literacy, PA in general and phoneme awareness in particular cannot be developed beyond basic levels, but that once the initial stages of literacy are gained, PA boosts literacy. This is specifically applied to phoneme awareness - the implication from most other studies, carried out in European contexts and languages, is that phoneme awareness is gained as a result of literacy training (Loureiro et al., 2004). Our followup study replicates our baseline finding that literacy is a necessary, but not a sufficient, condition for individuals to show phoneme awareness. It is possible that readers need specific types of literacy instruction to develop this. School instruction here tends to emphasise syllable, not phoneme, awareness; children teaching peers out of school are likely to replicate the school methods. This emphasis may also limit the possibilities of self-teaching as defined by Share (1995). Our results would however have benefitted from a more targeted measure of explicit phoneme awareness.

\section{Conclusions - What skills do children gain at home?}

At baseline we discovered that a sizeable number of children were learning to read 
words to the same accuracy level as their age mates, despite not having attended school. As discussed above, this is likely through informal peer tuition. A systematic investigation of this would enhance the current study. The number of children who became readers between $\mathrm{T} 1$ and $\mathrm{T} 2$ who were still out of school shows that informal learning continued in the interim. This ties in with various studies indicating that children's home language skills assist children in their school learning (Lekgoko \& Winskel, 2008; Veii, 2005; Veii \& Everatt, 2005). Some successful literacy interventions in the region have also attempted to work on home literacy (Dowd, Weiner, \& Mabeti, 2010; Pretorius \& Mokhwesana, 2009). If home literacy practices are as important as we suggest, we would recommend this type of intervention.

The finding that schooling history has become a predictor of literacy and PA at T2, and that only some PA skills improved at all over two years in children out of school, suggest further that schooling is nevertheless adding something to these children's literacy and PA skills. We can speculate that schooling may improve literacy and PA through additional concentrated practice, access to higher level reading books, or explicit classroom practices. Again, further systematic examination of these is warranted. However, our finding from the baseline study is confirmed and we can still conclude that children can, and do, learn to become accurate readers without classroom instruction in this setting.

\section{References}

Alcock, K. J., Jukes, M. C., Ngorosho, D., \& Deus, C. (2010). We don't have language at our house: Disentangling the relationship between phonological awareness and literacy. British Journal of Educational Psychology, 80(1), 55-76.

Alcock, K. J., Nokes, K., Ngowi, F., Musabi, C., McGregor, S., Mbise, A., . . Baddeley, A. (2000). The development of reading tests for use in a regularly spelled language. Applied Psycholinguistics, 21(4), 525-555.

Anthony, J. L., \& Lonigan, C. J. (2004). The nature of phonological awareness: Converging 
evidence from four studies of preschool and early grade school children. Journal of Educational Psychology, 96(1), 43-55.

Brombacher, A., Nordstrum, L., Davidson, M., Batchelder, K., Cummiskey, C., \& King, S. (2014). Tanzania. Retrieved from http://tinyurl.com/hwzj3lv

Bryant, P., MacLean, M., \& Bradley, L. L. (1990). Rhyme, language, and children's reading. Applied Psycholinguistics, 11, 237-252.

Chansa-Kabali, T., Serpell, R., \& Lyytinen, H. (2014). Contextual analysis of home environment factors influencing the acquisition of early reading skills in Zambian families. Journal of Psychology in Africa, 24(5), 410-419.

Combrinck, C., van Staden, S., \& Roux, K. (2014). Developing early readers: Patterns in introducing critical reading skills and strategies to South African children (Vol. 5).

Dowd, A. J., Weiner, K., \& Mabeti, F. (2010). Malawi Literacy Boost 2009 Year 1 Report: Prepared for Save the Children.

Grigorenko, E. L., Ngorosho, D., Jukes, M., \& Bundy, D. (2006). Reading in able and disabled readers from around the world: same or different? An illustration from a study of reading-related processes in a Swahili sample of siblings. Journal of Research in Reading, 29(1), 104-123.

Heugh, K. (2009). Into the cauldron: An interplay of indigenous and globalised knowledge with strong and weak notions of literacy and language education in Ethiopia and South Africa. Language Matters, 40(2), 166-189.

Jukes, M. C., Turner, E. L., Dubeck, M. M., Halliday, K. E., Inyega, H. N., Wolf, S., . . Brooker, S. J. (submitted). Teacher professional development and text messages support for improved literacy instruction in Kenya: a cluster randomized trial. Educational Evaluation and Policy Analysis. 
Laguarda, A. I., \& Woodward, W. P. (2013). They own this: Mother tongue instruction for indigenous Kuku Children in Southern Sudan. School Psychology International, 34(4), 453-469.

Landgraf, S., Beyer, R., Hild, I., Schneider, N., Horn, E., Schaadt, G., . . . van der Meer, E. (2012). Impact of phonological processing skills on written language acquisition in illiterate adults. Developmental Cognitive Neuroscience, 2, Supplement 1(0), S129-S138.

Lekgoko, O., \& Winskel, H. (2008). Learning to read Setswana and English: Cross-language transference of letter knowledge, phonological awareness and word reading skills. Perspectives in Education, 26(4), 57-73.

Loureiro, C. D., Braga, L. W., Nascimento, L. D., Nunes, G., Queiroz, E., \& Dellatolas, G. (2004). Degree of illiteracy and phonological and metaphonological skills in unschooled adults. Brain and Language, 89(3), 499-502.

Malda, M., Nel, C., \& van de Vijver, F. J. R. (2014). The road to reading for South African learners: The role of orthographic depth. Learning and Individual Differences, 30, 34-45. Matjila, D. S., \& Pretorius, E. J. (2004). Bilingual and biliterate? An exploratory study of Grade 8 reading skills in Setswana and English. Per Linguam: a Journal of Language Learning, 20(1), p. 1-21.

Melby-Lervåg, M., Lyster, S.-A. H., \& Hulme, C. (2012). Phonological skills and their role in learning to read: a meta-analytic review. Psychological Bulletin, 138(2), 322.

Morais, J., Bertelson, P., Cary, L., \& Alegria, J. (1986). Literacy training and speech segmentation. Cognition, 24(1-2), 45-64.

Musonda, M.-G. (2011). Literacy Behaviours Which Pre-schoolers exhibit in selected households of Lusaka. (MEd), University of Zambia.

Muter, V., Hulme, C., Snowling, M., \& Taylor, S. (1998). Segmentation, not rhyming, predicts early progress in learning to read. Journal of Experimental Child Psychology, 
71(1), 3-27.

Muter, V., Hulme, C., Snowling, M. J., \& Stevenson, J. (2004). Phonemes, Rimes, Vocabulary, and Grammatical Skills as Foundations of Early Reading Development: Evidence From a Longitudinal Study. Developmental Psychology, 40(5), 665-681.

Nampijja, M., Kizindo, R., Apule, B., Lule, S., Muhangi, L., Lewis, C., . . Alcock, K. J. (submitted). The Role of the Home Environment in Cognitive Performance of Children: Beyond Poverty and Education. International Journal of Behavioral Development.

Ngorosho, D. (2011). Reading and writing ability in relation to home environment: A study in primary education in rural Tanzania. Child Indicators Research, 4(3), 369-388.

Pretorius, E. J., \& Mokhwesana, M. M. (2009). Putting reading in Northern Sotho on track in the early years: Changing resources, expectations and practices in a high poverty school. South African Journal of African Languages, 29(1), 54-73.

Pretorius, E. J., \& Naudé, H. (2002). A culture in transition: poor reading and writing ability among children in South African townships. Early Child Development and Care, 172(5), 439-449.

Share, D. L. (1995). Phonological recoding and self-teaching: Sine qua non of reading acquisition. Cognition, 55(2), 151-218.

Trudell, B., Dowd, A., Piper, B., \& Bloch, C. (2012). Early grade literacy in African classrooms: Lessons learned and future directions. Paper presented at the Triennale Meeting of Association for the Development of Education in Africa (ADEA).

UNESCO. (2015a). A growing number of children and adolescents are out of school as aid fails to meet the mark. Retrieved from http://tinyurl.com/j3yrzds

UNESCO. (2015b). Literacy and non-formal education. Retrieved from http://www.unesco.org/new/en/dakar/education/literacy/

Veii, K. R. (2005). Innovations and developments in psychology and education: Do literacy 
difficulties in Namibian Herero-English Bilingual school children occur in one or both languages. TRANS. Internet-Zeitschrift für Kulturwissenschaften, 16.

Veii, K. R., \& Everatt, J. (2005). Predictors of reading among Herero-English bilingual Namibian school children. Bilingualism: Language and Cognition, 8(3), 239.

Williams, E. (1998). Investigating Bilingual Literacy: Evidence from Malawi and Zambia. Education Research Paper: ERIC.

Wilsenach, C. (2013). Phonological skills as predictor of reading success: An investigation of emergent bilingual Northern Sotho/English learners. Per Linguam: a Journal of Language Learning, 29(2), 17-32.

World Bank. (2015). World Bank Poverty Data. Retrieved from http://data.worldbank.org/topic/poverty 